\title{
Variation in the Colonization of Artificial Substrates by Mangrove Root Fouling Species of the Port Royal Mangrove Lagoons in the Eutrophic Kingston Harbour, Jamaica
}

\author{
Tovia Elliott, Gale Persad, Mona Webber* \\ Department of Life Sciences, University of the West Indies (Mona Campus), Kingston, Jamaica \\ Email: *mona.webber@uwimona.edu.jm
}

Received February 14, 2012; revised March 19, 2012; accepted April 11, 2012

\begin{abstract}
The aim of this study was to investigate temporal changes in mangrove root fouling species settled on artificial substrates in the mangrove zone of the Port Royal lagoons and to determine the effect of stress as part of a larger project to determine appropriate indicators of eutrophication in mangrove lagoons. Five Perspex@ panels were suspended in the prop root zone at five contrasting stations within the Port Royal mangroves and the fouling organisms were monitored fortnightly using underwater digital photography. Nine taxonomic categories of epibionts were recorded of which the most prevalent group was the ascidians. Barnacles and hydroids were initially found to have established on the artificial substrates at all stations but were quickly replaced by ascidians and bryozoans at most. Species composition was similar between all stations by the end of the study, however, the dominant taxa were different. Sheltered lagoons like Fort Rocky lagoon (north and south) had a clear dominance of non-shelled species (ascidians and polychaetes) by the end of the study, while molluscs-bivalves and barnacles dominated Hurricane Refuge lagoon. This station, deemed to be experiencing greatest stress due to exposure to the eutrophic Kingston Harbour, also had the greatest proportion of shelled taxa represented in the epibiont biomass at the end of the study. Differences in biomass and species composition of root fouling species can therefore be used to indicate water quality in the mangrove lagoons.
\end{abstract}

Keywords: Mangrove Lagoons; Water Quality Indicators; Root Fouling Species; Eutrophication

\section{Introduction}

Mangrove lagoons house important intertidal communities and provide habitat and substrate for a diverse range of species [1]. However, as a consequence of their location at the transition zone between terrestrial and marine environments, mangrove species must be able to deal with the stresses associated with the habitat. These include temperature and salinity fluctuations, low dissolved oxygen, high turbidity and nutrients from land runoff.

The mangrove forest, along with the closely associated adjacent lagoon and epibiont prop root communities are of tremendous ecological value. Mangrove lagoons are vital nursery areas for commercially important finfish and shell-fish species and mangrove forests form hydrodynamic barriers protecting against coastal erosion. Furthermore, mangrove ecosystems are well known as areas of high biodiversity. In particular, the sub-tidal prop roots of the red mangrove, Rhizophora mangle, provide

"Corresponding author. substrate and habitat for a wide range of sessile organisms [2-4]. Consequently, diverse epibiont assemblages of often colourful sponges, bivalves, barnacles, polychaetes and tunicates (colonial and solitary) are found on submerged roots [5].

The Port Royal mangroves, located along the $10 \mathrm{~km}$ long Palisadoes tombolo are of particular importance in shoreline stabilization and protection of the communities associated with the Kingston Harbour and the Palisadoes tombolo. Consequently, the biological integrity of the Port Royal mangroves needs to be conserved which can only be achieved through an understanding of the community dynamics of the ecosystem [6]. Recent studies have examined the ecology of individual epibionts of Caribbean mangrove root communities, such as ascidians [7], bryozoans [8] and sponges [9]. However, few studies have been conducted in Jamaica that examine the variation in the entire prop root fouling community.

One way of examining these sessile epibiont community dynamics is through the study of succession in the 
fouling species. Succession is commonplace in descriptive ecology with many studies emphasizing temporal changes in individual species. However, the use of successional stages in mangrove ecology, at the community level of organization, has not been fully explored.

Successional stages or sequences occur over wideranging time scales and are usually a consequence of various underlying mechanisms [10]. Accurate prediction of species distribution patterns is difficult, mainly due to the different responses of each species to spatial and temporal variation in the environment. Therefore, the use of taxonomical or functional groupings facilitates investigations into community relationships [5] and aids in the identification of community responses to stress.

The aim of the current study was to investigate changes in fouling species on artificial substrates in the mangrove zone of the Port Royal lagoons and to determine the effect of different stresses, as part of a larger project to determine appropriate water quality indicators for mangrove lagoons.

\section{Site Description \& Station Selection}

Kingston Harbour (Figure 1) is situated on the south coast of Jamaica between $17^{\circ} 57^{\prime} \mathrm{N}$ and $58^{\prime} \mathrm{N}$ and $76^{\circ} 44^{\prime} \mathrm{W}$ to $52^{\prime} \mathrm{W}$. It extends $16.5 \mathrm{~km}$ in an east to west direction and
$6.5 \mathrm{~km}$ in a north to south direction with a total surface area in excess of $50 \mathrm{~km}^{2}$ [11]. The city of Kingston forms the northern and eastern margins of the Harbour while the $10-12 \mathrm{~km}$ long Palisadoes tombolo delimits the Harbour on the south [6,11].

The Harbour has been described as polluted with the sources of contamination being nutrients (nitrogen and phosphorus), pesticides, herbicides and bacteria. These reach the Harbour via freshwater input from the Rio Cobre, Duhaney River and the Sandy Gully as well as 28 minor gullies which drain the city of Kingston [6,11]. Contaminant sources include agricultural runoff, domestic sewage and industrial effluents [11].

The Port Royal mangrove swamp forms part of the southern border of the Kingston Harbour and is located on the Palisadoes tombolo between $17^{\circ} 56^{\prime} \mathrm{N}$ and $76^{\circ} 49^{\prime} \mathrm{W}$ [12]. It covers approximately 10 ha [13] with 0.77 ha being dominated by fringe Rhizophora mangle communities on its seaward borders [14,8]. The entire area has mangrove lagoons and channels bordered by large islands of mangrove forests [15]. The mangrove area is reported by Goodbody (2003a) [6] as being the most significant remaining mangrove forest stand on the southern shore of the Kingston Harbour to the east of the town of Port Royal (Figure 1).

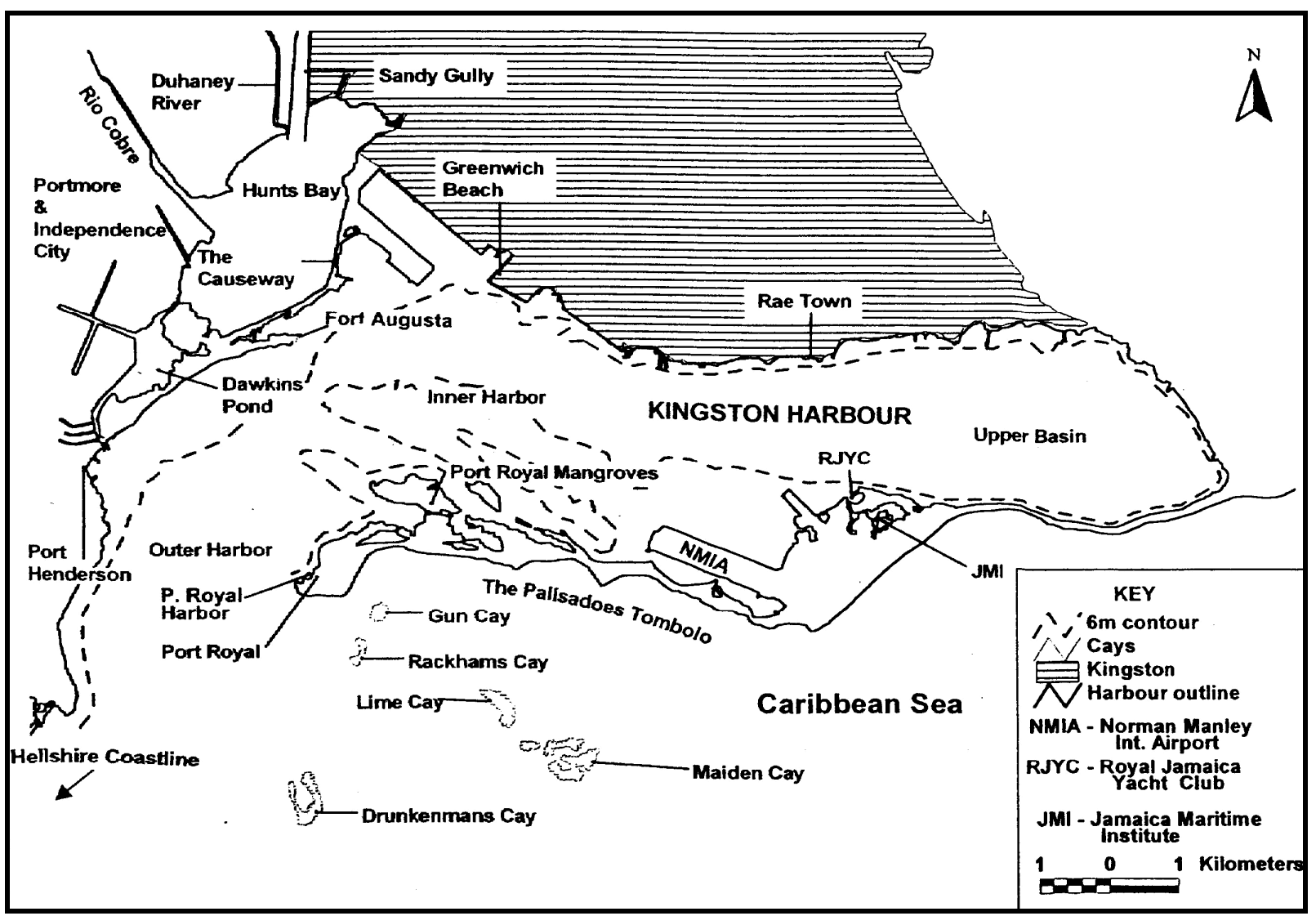

Figure 1. Map of Kingston Harbour showing the location of the Port Royal mangroves. 
The study was conducted in three of the mangrove lagoons found in the Port Royal mangroves: Hurricane Refuge lagoon, Fort Rocky lagoon and Cemetery lagoon [7]. These lagoons experience differing levels of exposure to the polluted Kingston Harbour waters.

Preliminary observations and supplementary information about the area facilitated the selection of five sampling stations (Figure 2), which represented relatively pristine areas (Fort Rocky lagoon) and more disturbed sites (Hurricane Refuge lagoon) within the Port Royal mangroves.

\section{Sampling Techniques}

At each station a $20 \mathrm{~m}$ long stretch of mangroves was selected as the sampling site. Site selection was based on the following criteria:

- relatively high Rhizophora mangle (red mangrove) prop root densities.

- at least 20 m length of coastline of healthy, "good”, unanchored prop roots.

- occurring in more or less regular bands and

- mangrove roots neither very branched nor attached to the bank at the edge of the lagoon.

These criteria were developed after general observations in the study area and based on the need to sus- pend the artificial substrates freely within the area of the red mangrove prop roots.

The limits of each $20 \mathrm{~m}$ long sampling band were permanently marked and five artificial substrates placed at each station to simulate the natural prop root community [16]. These artificial substrates were Perspex panels of dimensions $60 \mathrm{~cm} \times 15 \mathrm{~cm}$ with holes drilled within $2.5 \mathrm{~cm}$ of the top, bottom and side edges through which coloured ties serving as georeferencing markers were placed. Pairs of Perspex panels were sealed together forming a "sandwich" which was held together with silicone adhesive. Both sides of each panel were photographed from the same angle on each sampling occasion to indicate the changes in the epibiont community over time.

Sampling was conducted fortnightly over a ninemonth period from September 2003 to June 2004 during 0700 - 1300 hours. The sampling regime included digital photographs of all panels at each station as well as measurements of physico-chemical parameters. Photographs of one side of the panels were taken using a Nikon Coolpix 3.0 mega pixel digital camera. The panels were consistently oriented so that the yellow georeference cabletie was always located on the right side of the panel, to differentiate between the front and back of the panels.

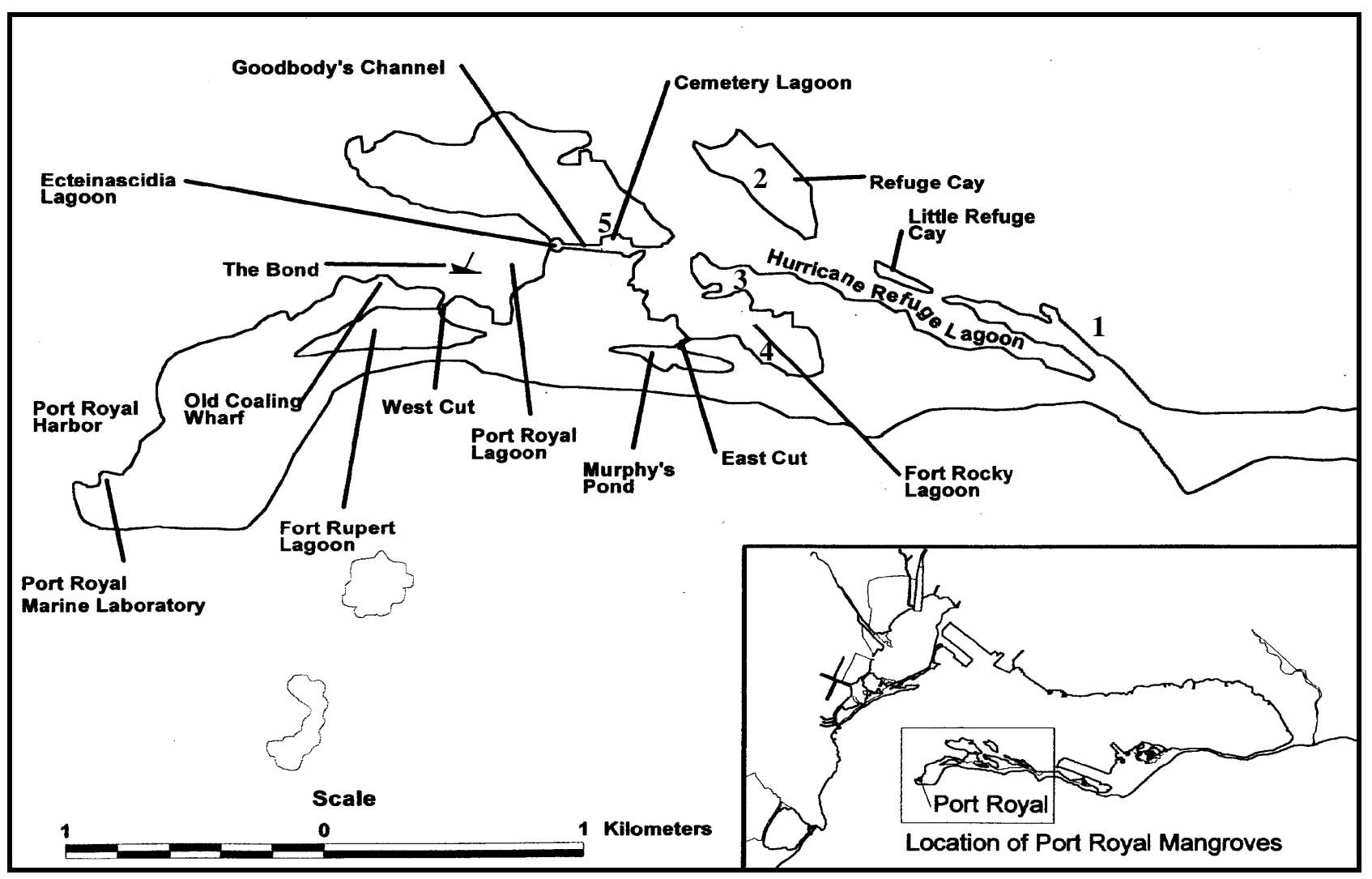

Figure 2. Map of the Port Royal Mangroves showing the 5 stations sampled. Map used with permission from Goodbody, 2003. 
Photographs were examined and a taxonomic species list for each panel was generated. Each epibiont taxon was assigned to 1 of 9 categories based on morphology, life history and taxonomic affiliation, similar to the criteria used by Farnsworth and Ellison (1996) [5] in their study of Belizean prop root communities. The categories used were: sponges (encrusting and massive), polychaetes, gastropods, barnacles, bivalves, ascidians (solitary and colonial), bryozoans and algae. Soft-bodied cnidarians and worms, such as flatworms and nudibranchs, were placed in a category called "other". In addition to species composition, photographs were analysed for changes in dominant taxa with the latter being facilitated by the use of the computer program Coral Point Count with Excel extensions (CPCe) version 3.4 [17]. Images were uploaded and image scaling was performed whereby known distances along images were calibrated. Area/length analysis was then performed on each image where perimeters of specific organisms were outlined and their area of coverage calculated. Total species richness was measured as the total number of species present at each station [8].

At the end of the sampling period, the panels were taken back to the laboratory where organisms were removed and the biomass of each type determined as dry weight and ash free dry weight. The drying and ashing techniques used in this study were similar to those employed by McDonald et al. (2003) [15].

Significant temporal variation was determined using analysis of variance (ANOVA) within Statistica Version 6.0 (1998 edition). Raw data were transformed where necessary after assessment using normal probability plots [5]. Station grouping and ranking was carried out using the post hoc test, Tukey's Honest Significant Difference (HSD).
Pearson's Product-Moment (PPM) correlations were used to generate a correlation matrix and showed the strength and direction of linear relationships between biological and physicochemical data. Correlations range from -1 to +1 , with a value of 0 indicating no correlation [18].

\section{Results}

Temporal variation in species richness of epibionts on the artificial panels was found to be significant (MANOVA, $\mathrm{p}<0.001)$. In general, similar temporal changes in species richness were seen at all stations (Figure 3). Mean number of species steadily increased over time before either stabilizing or decreasing at the end of the study period. A decrease at the end of the sampling period was observed at all stations with the exception of those in Fort Rocky Lagoon North and South banks where plateaus were observed in mean species richness (Figure 3).

As an index of importance, the frequency of occurrence over the sampling period and the range of stations at which the dominant taxonomic groups occurred were examined (Figure 4). The nudibranchs were widely distributed across stations but showed low percentage occurrence, being recorded only once over the sample period at most stations. In sharp contrast, the bivalve Perna viridis and the bryozoan Schizoporella sp. were widespread, but had a higher frequency of occurrence, each being present on more than $60 \%$ of the sampling occasions. Thus they were deemed important epibionts in the Port Royal mangrove lagoons.

Few taxa seemed to be restricted to particular stations and some rare and localized species were observed. Examples of such were the alga Enteromorpha sp., the ascidian Phallusia nigra, which were both recorded on only

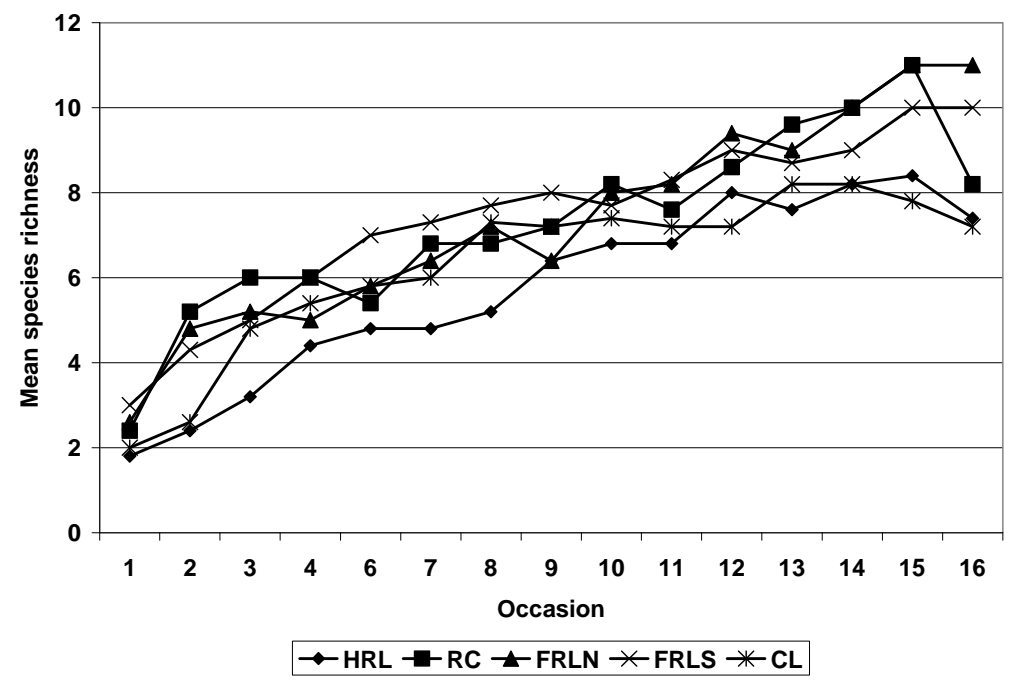

Figure 3. Species distribution across stations and ranking based on frequency of occurrence. Rank $1=7 \%$ to $20 \%$ occurrence; rank $2=21 \%$ to $40 \%$; rank $3=41 \%$ to $67 \%$; rank $4=68 \%$ to $87 \%$; rank $5=88 \%$ occurrence. 
one occasion. Most of the sessile epibionts recorded over the study period were widely distributed and occurred frequently, i.e. occurring at 3 or more stations on many sampling occasions. The most frequent and widely distributed taxa recorded were brown algae, Crassostrea rhizophorae and Schizoporella sp. (Figure 4).

\subsection{Changes in Colonization of Taxonomic Groups at Each Station}

Hurricane Refuge Lagoon (HRL) had algae and polychaetes being amongst the early colonizers. Polychaetes and Hydroids were the least speciose over time. However, as time progressed new taxonomic groups were represented as the number of species increased (Figure 5). Molluscs and barnacles were also early colonizers and molluscs were the most speciose group at HRL. Mean algal species richness steadily declined over time to the point of near disappearance from the community on the artificial. The decrease in mean numbers of algal species coincided with an increase in barnacle species. Ascidians and sponges entered the community towards the middle and end of the sample period at occasion 9 and 11, respectively.

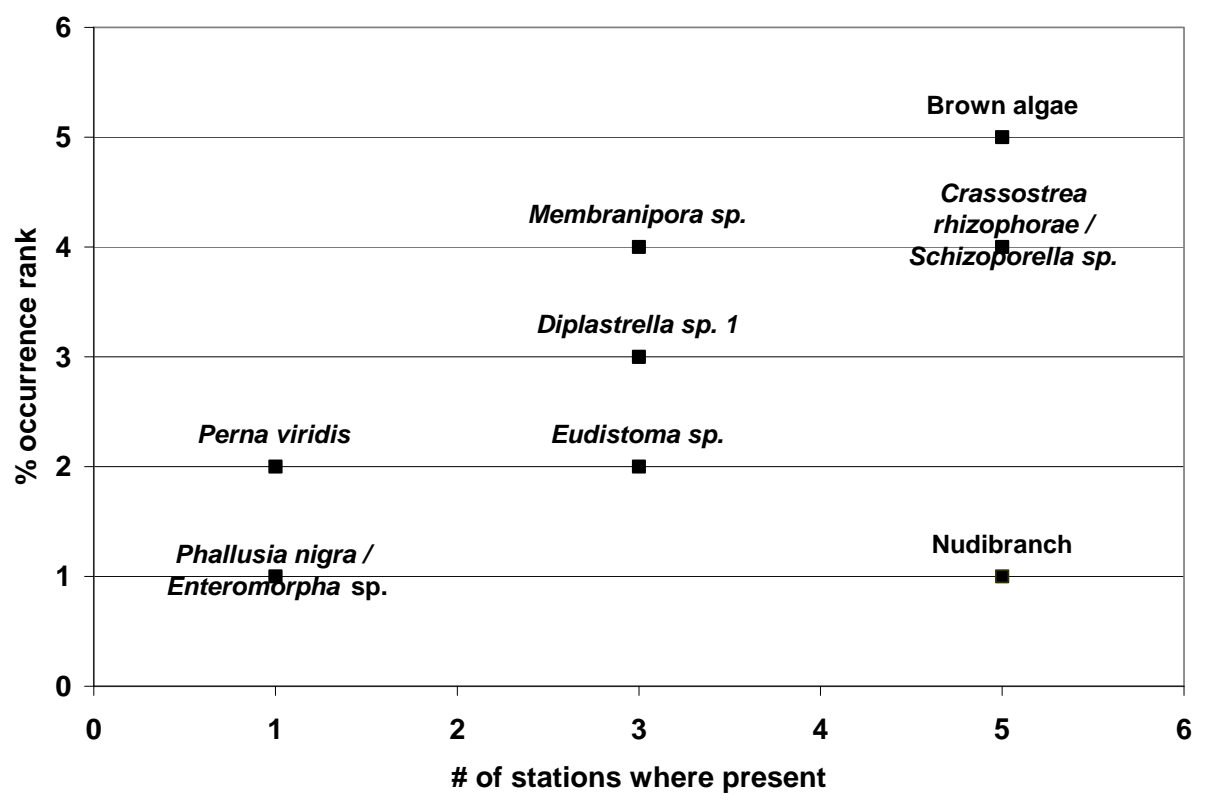

Figure 4. Variation in mean species richness for all stations over time (occasions sampled).

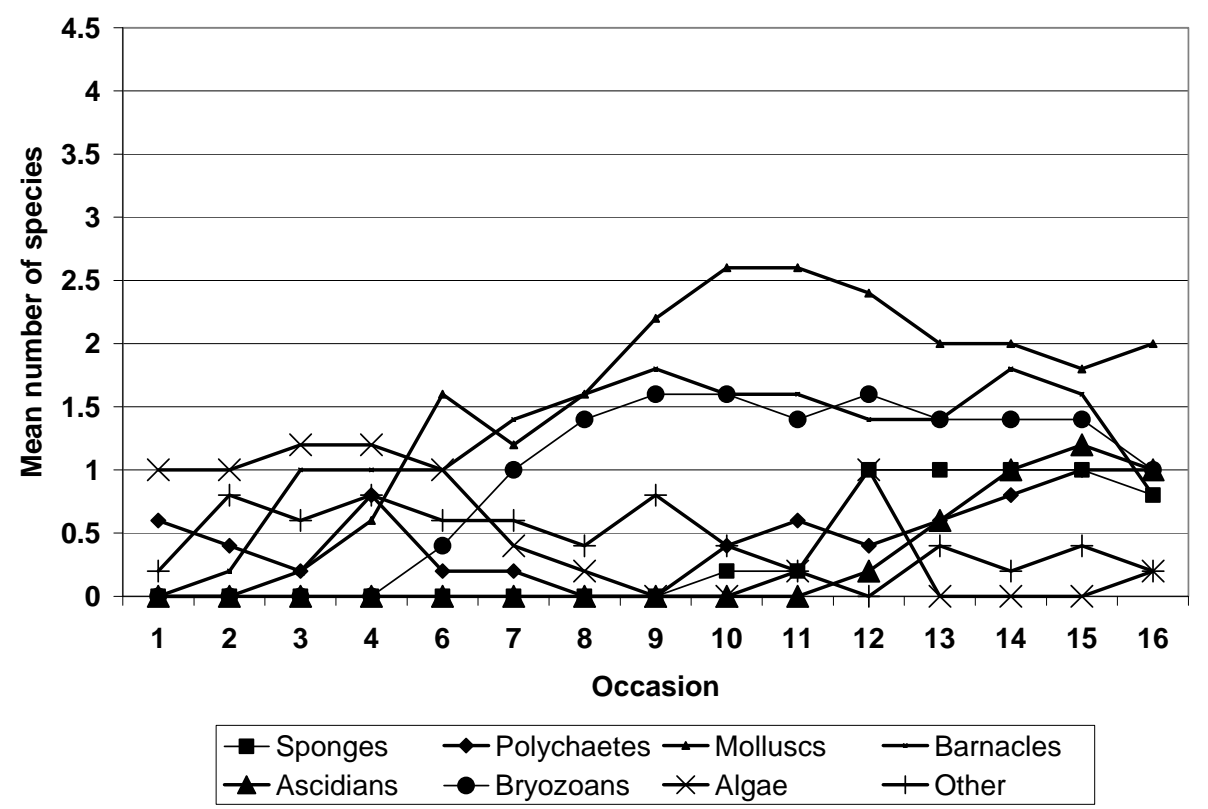

Figure 5. Changes in taxonomic group species richness at Hurricane Refuge Lagoon. 
All 8 taxonomic groups were represented in the epibiont community from HRL on the last sampling occasion (occasion 16) with mean species richness declining slightly for all groups with the exception of the molluscs; which were mostly bivalves.

Refuge Cay (RC) has algae, polychaetes and ascidians as the primary colonizers of sessile communities on the artificial panels. Barnacles also comprised part of the pioneer community while molluscs were first recorded at occasion 4 after which a sharp increase was noted in mean numbers of species. Bryozoans followed by ascidians displayed the highest increase in mean species richness over time at RC with species settling from the first sampling occasion. The group was highly persistent, with mean bryozoan species richness increasing with time up to occasion (Figure 6). However, ascidians were the most speciose group at RC. Sponges were only recorded at RC at occasion 11 and mean species richness was generally low throughout the sample period. The mean number of species of all taxonomic groups, with the exception of the bryozoans, decreased from occasion 15 on panels at Refuge cay.

Fort Rocky Lagoon North (FRLN) had a similar pioneer community in composition to that observed at HRL where algae, polychaetes and the group "other” were the earliest colonizers. In addition to these groups, Ascidians were also present at the start of the study and displayed a high persistence with species being recorded on each sample occasion (Figure 7). Algal species numbers remained constant throughout the sample period with very

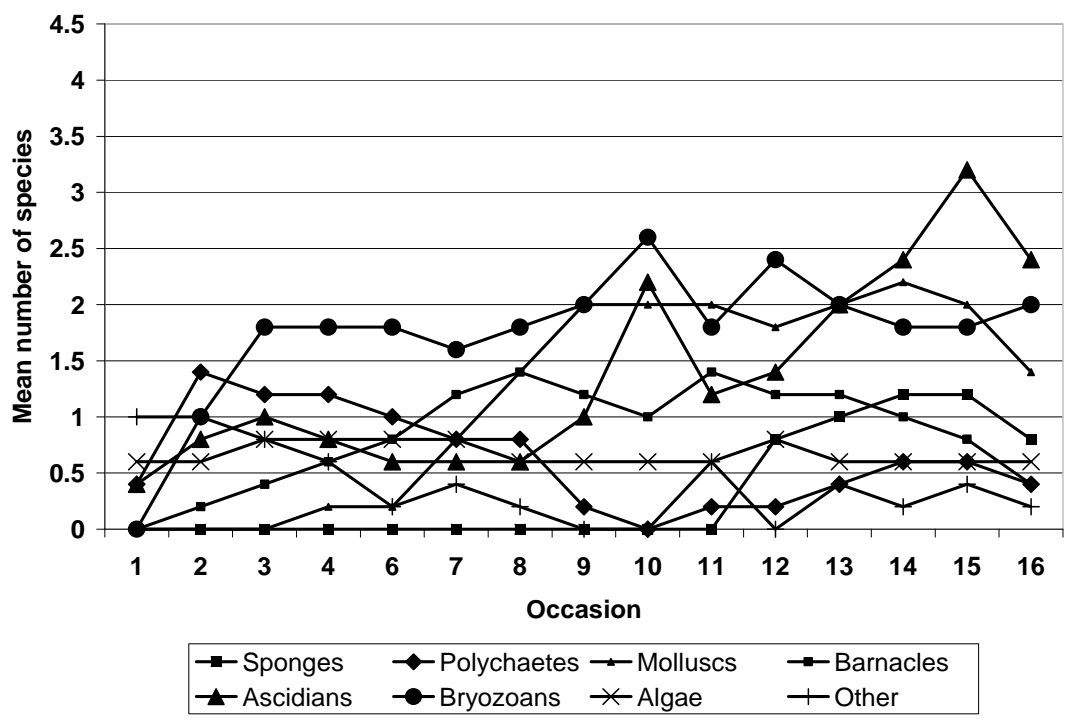

Figure 6. Changes in taxonomic group species richness at Refuge Cay.

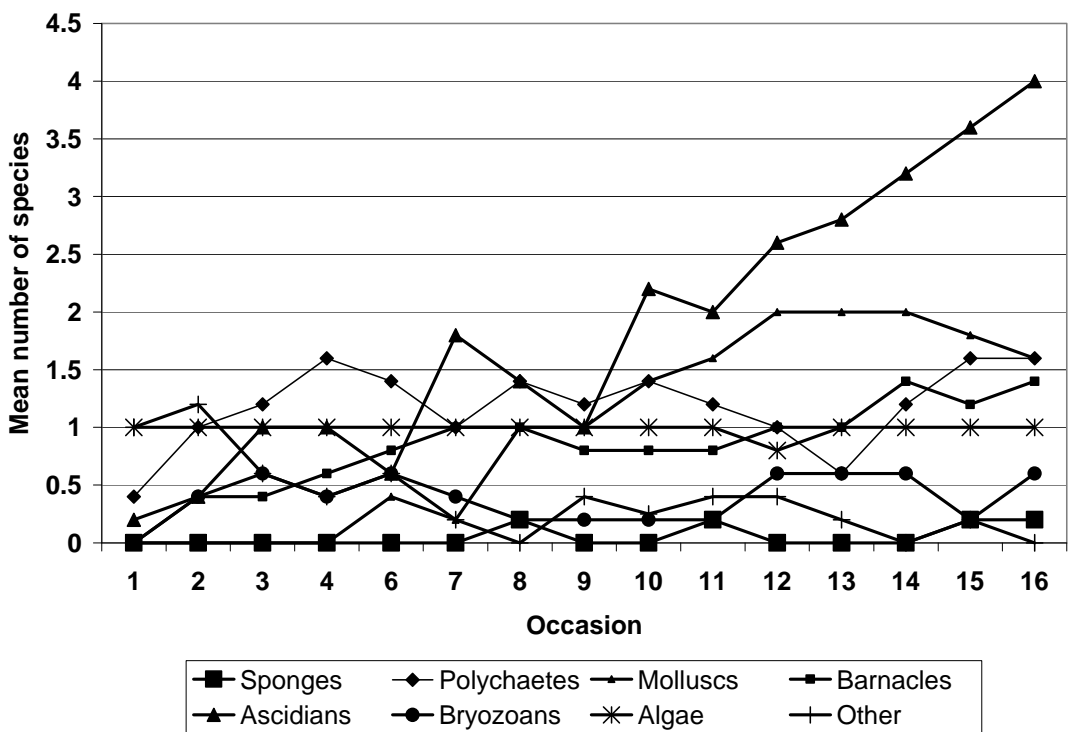

Figure 7. Changes in taxonomic group species richness at Fort Rocky Lagoon North. 
little fluctuation observed. Mean species richness of ascidians and polychaete displayed a similar trend as the ascidians up until occasion 10 after which numbers generally decreased. Sponges were noticeably absent from the community until the middle of the sample period (around occasion 8) where species were observed for two occasions before disappearing from the community. The sponges were also the least speciose group at FRLN and their arrival in the community coincided with a decrease in the number of ascidian species. Molluscs and barnacles were first observed after occasion 2 and 4, respectively and the general trend was a steady increase in mean numbers of species up to occasion 12 where numbers stabilized. Mean bryozoan species richness was very low at FRLN with mean number never exceeding 1. Overall, mean numbers of species were more or less con- stant with some fluctuations throughout the sample period and generally stable from occasion 8 through to occasion 11. Ascidians were clear dominants by the end of the sampling period with species number more than twice that of any other group (Figure 7).

Fort Rocky Lagoon South (FRLS) showed similarities in species composition to FRLN with at least 4 of the 8 taxonomic groups being represented at the latter (Figure 8). Algal species numbers were the same as recorded at FRLN with mean numbers of species being constant throughout the sample period.

Cemetery Lagoon (CL) had the smallest pioneer community of the 5 stations investigated in terms of species composition with only 2 taxonomic groups being recorded on the first sampling occasion (Figure 9). Algae were the earliest colonizers of artificial substrates at CL with an

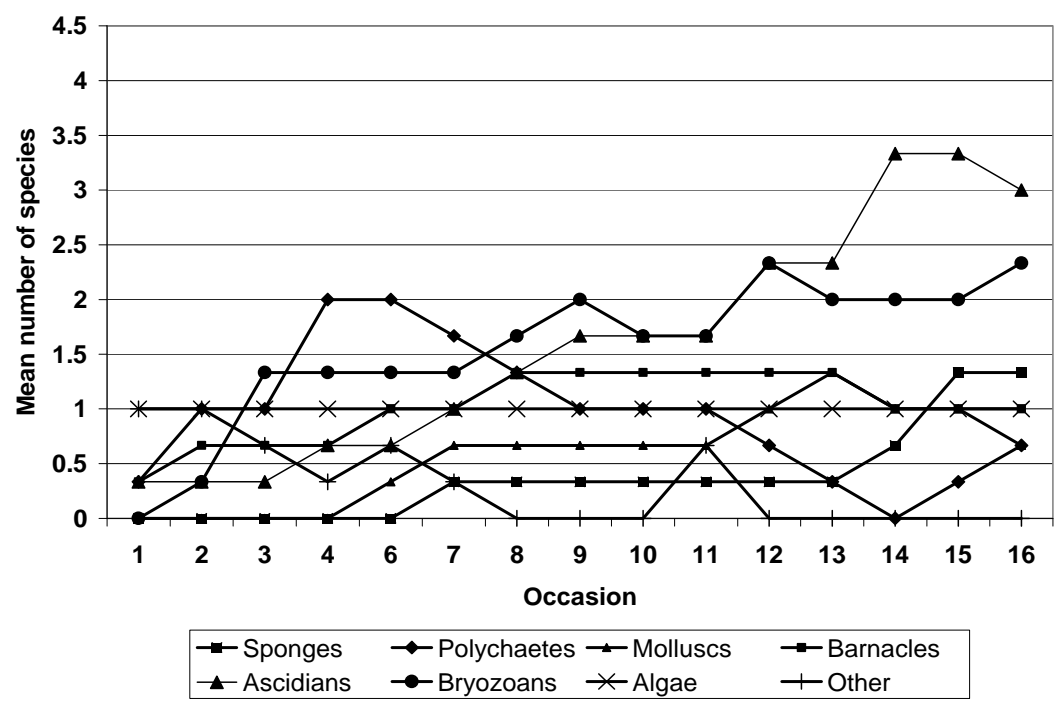

Figure 8. Changes in taxonomic group species richness at Fort Rocky Lagoon South.

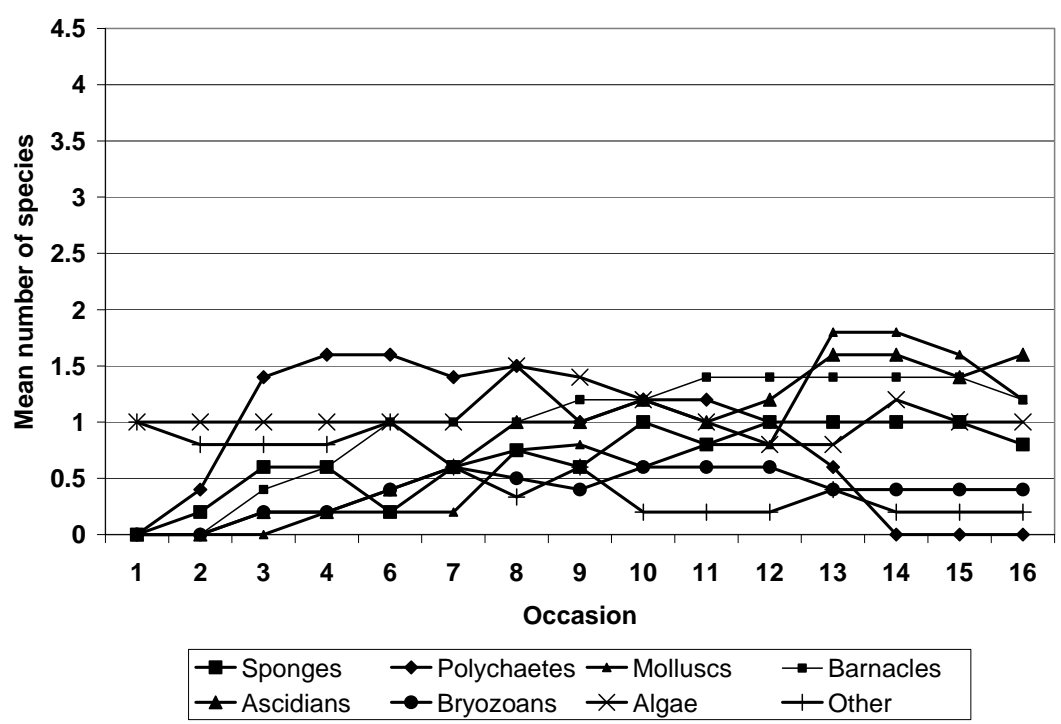

Figure 9. Changes in taxonomic group species richness at Cemetery Lagoo. 
average of 1 species being recorded per group on occasion 1 . However, by occasion 3 at least 6 of the 8 taxonomic groups were represented in the community as was also the case for the other 4 stations previously mentioned.

Mean taxonomic group species richness at CL never exceeded 2. Molluscs, ascidians and barnacles displayed similar patterns of species richness with steady increases in numbers of species over time and negligible fluctuations. In contrast, species richness of sponges fluctuated over time but mean number of species generally increased towards the end of the study. The bryozoans were the least speciose group and algae were essentially constant throughout the sample period with more fluctuations being seen towards the latter part of the study (Figure 9).

\subsection{Biomass}

Comparison of the biomass of shelled and un-shelled taxa (Table 1) done at the end of the study revealed a dominance of shelled taxa (barnacles and bivalves) at Hurricane Refuge Lagoon (HL) and Cemetery Lagoon (CL). Substrates at HL had over $60 \%$ shelled organisms, which is consistent with the observations made during the study.

\subsection{Indicator Species}

Potential species that might be used as indicators of eutrophication were investigated based on whether they were widely distributed and had high frequency of occurrence (cf. Figure 4). The encrusting bryozoan Schizoporella sp. was the only species that satisfied these criteria, and colonization of panels by this bryozoan was generally rapid with colonies being established within the first four sampling occasions (Figure 10) and persisting for the rest of the sample period (Figure 11).
As can be seen from the plates, colonies generally increased in size over time, usually growing around other species such as solitary ascidians. While the encrusting bryozoan Schizoporella sp. rapidly overgrew many other epibiont species on panels, there was never any overgrowth observed between colonies of the same species (Figures 10-13). This coincided with the findings of Osman (1977) [19] who reported cessation of growth at the point of contact between $S$. errata colonies contrasting those of $S$. biaperta which showed a re-direction of growth.

\section{Discussion}

Succession can be loosely defined as change in species composition over time culminating in an equilibrium of species, where change is either negligible or results in no new species being introduced. Both Odum (1963) [20] and Osman (1977) [19] concluded that succession implied both a competitive hierarchy of species and an order of colonization whereby the presence of one species or group was necessary for invasion by the next group. In summary, succession is directional and ordered. Osman (1977) [19] also suggested that if the order of change in the species composition was repeated on a yearly basis in the community, then seasonality rather than succession would be occurring.

Table 1. Biomass (grams ash free dry weight) of epibionts at each station on the artificial pannels.

\begin{tabular}{cccccc}
\hline STATIONS & HR & RC & FRN & FRS & CL \\
\hline Shelled & 1.9629 & 1.4664 & 1.4139 & 0.7856 & 0.9842 \\
Non-shelled & 1.1242 & 1.8850 & 1.6386 & 0.9487 & 0.9150 \\
Total Biomass & 3.0871 & 3.3515 & 3.0525 & 1.7342 & 1.8992 \\
\% Shelled & 63.5842 & 43.7554 & 46.3197 & 45.2967 & 51.8221 \\
\hline
\end{tabular}

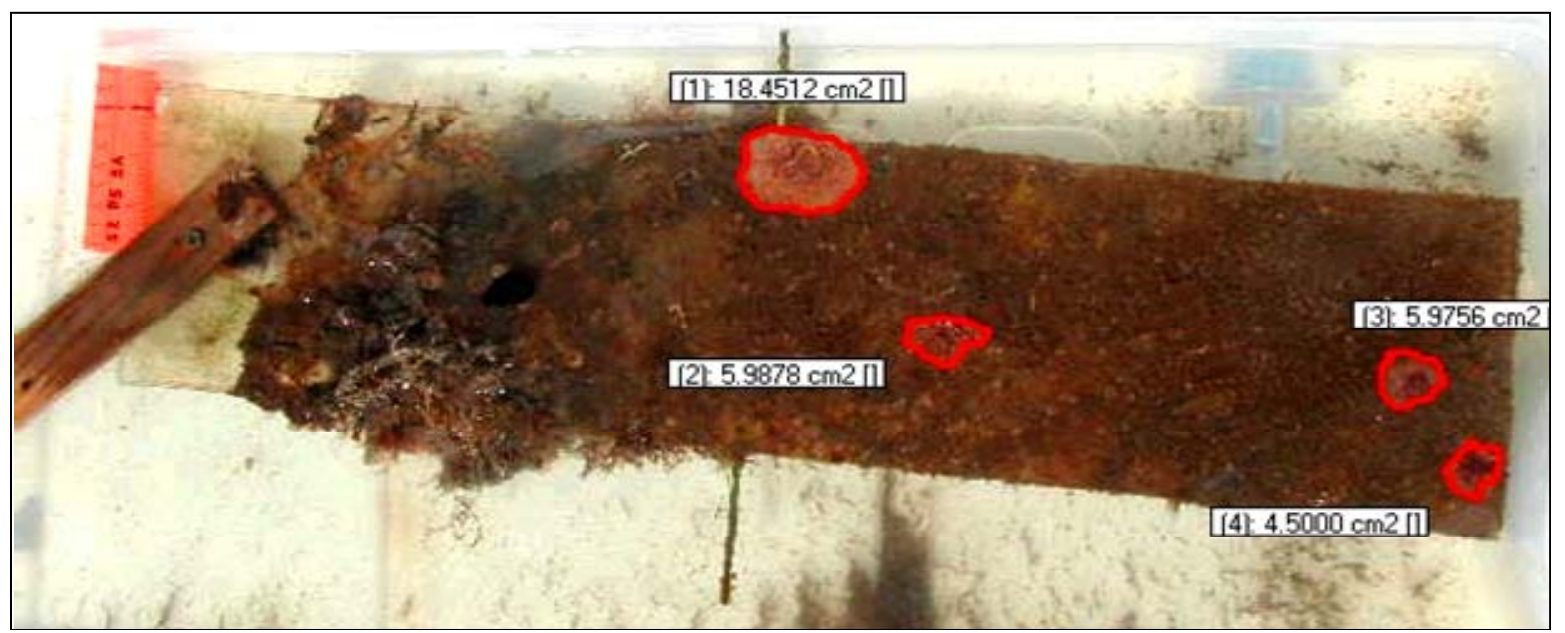

Figure 10. Schizoporella on Perspex panel at sampling occasion \#4. (Area of coverage given in $\mathrm{cm}^{2}$ ). 


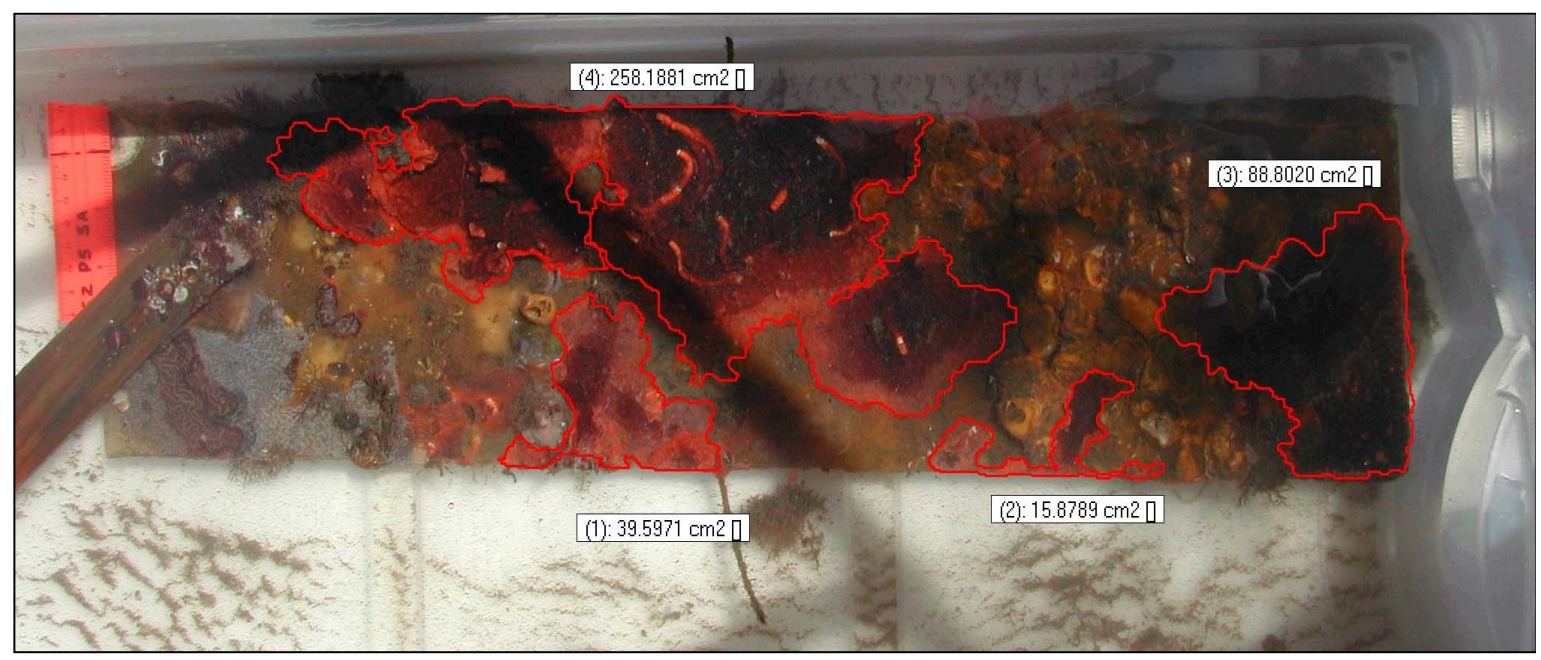

Figure 11. Schizoporella on Perspex panel at sampling occasion \#16. (Area of coverage given in $\mathrm{cm}^{2}$ ).

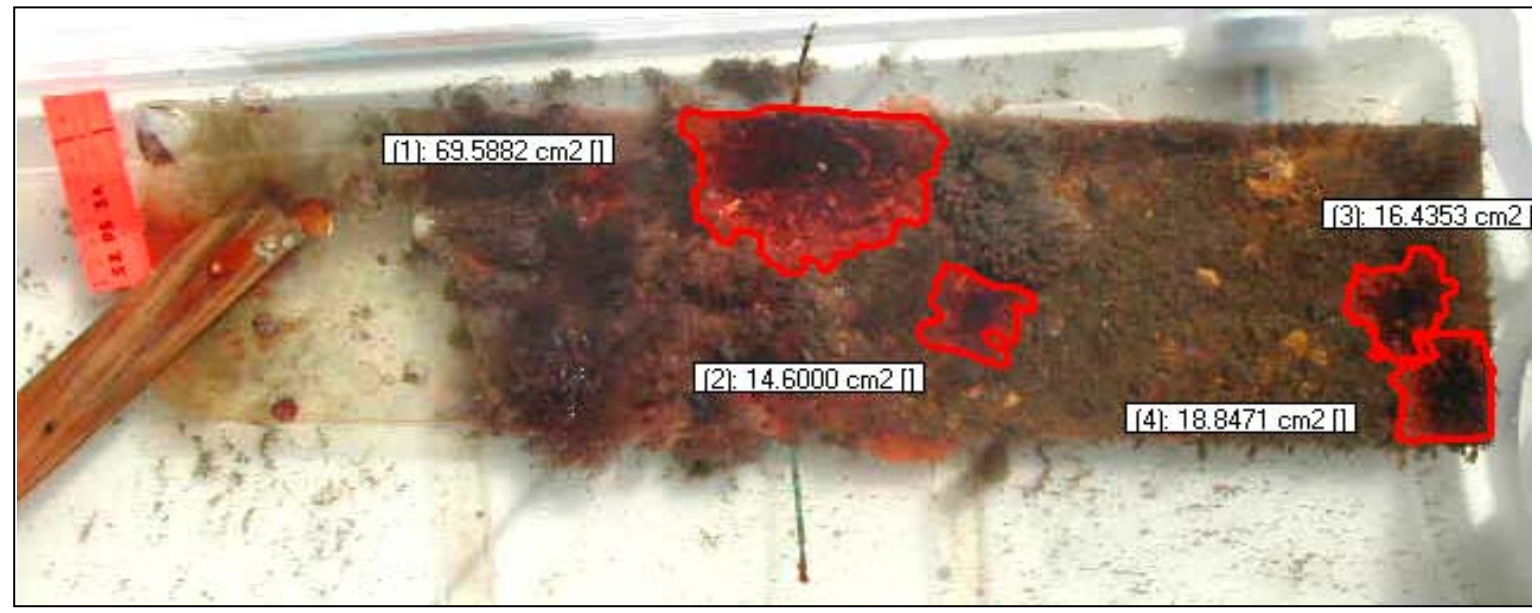

Figure 12. Schizoporella on Perspex panel at sampling occasion \#9. (Area of coverage given in $\mathrm{cm}^{2}$ ).

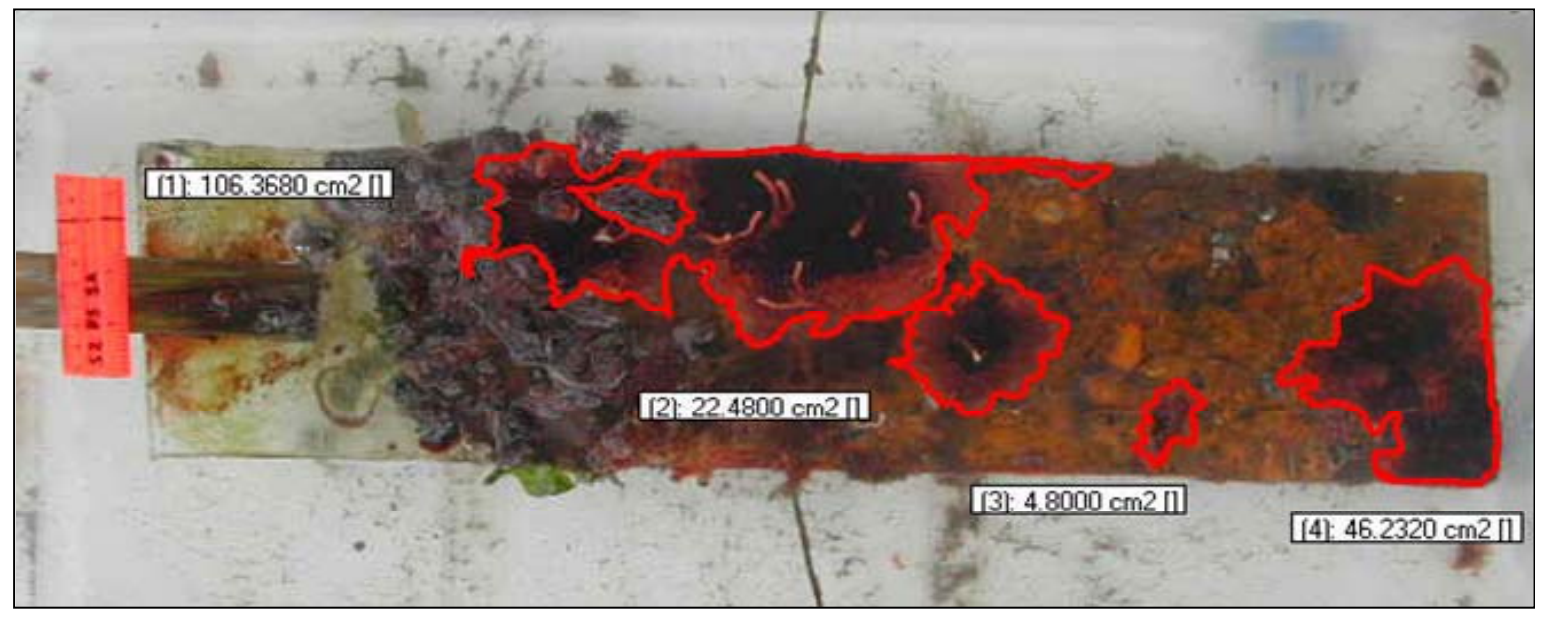

Figure 13. Schizoporella on Perspex panel at sampling occasion \#13. (Area of coverage given in $\mathrm{cm}^{2}$ ).

The mangrove root communities investigated proved to be extremely dynamic as indicated by the high temporal variability in all biota recorded over the study period.
The use of a fortnightly sampling interval facilitated the observation of numerous changes occurring within the root community, which had previously also been high- 
lighted by Bingham and Young (1995) [16]. They concluded that a much more dynamic community is perceived at a shorter sampling interval as important ecological processes occur on short time scales in the mangrove habitat.

Species disappearance from the community was not always the result of physiological stresses from variations in physicochemical parameters. Bingham and Young (1995) [16] in their study of Floridian mangroves, indicated that tidal currents might have a greater influence due to current induced abrasion between roots. Species often grew too heavy to be supported by the roots and constant contact between roots resulted in some species being sloughed off as was evidenced by pieces of species-laden roots found lying on the lagoon floor. This could also be the reason for large colonies disappearing completely from successive photographs.

The major trends in succession may be classified in terms of: species structure, organic structure (biomass) and energy flow (community metabolism) [20]. With regard to species structure, there is a tendency for species richness and diversity to increase with succession, such that initial observations often show rapid changes in species composition followed by more gradual changes in later successional stages [20]. Results from the current study corresponded with this expected trend. At all stations a similar temporal pattern in species richness was observed, such that richness increased over time before either stabilization or reduction at the end of the sampling period.

The variation in mean species richness over time from this study also supported the suggestion by Odum (1963) [20] that species initially important in the pioneer stages of succession are usually not dominant in the later stages, resulting in a characteristic stair-step graph. These results are also similar to those of Goodbody (1993) [4] in his study of Jamaican mangrove root communities in the Port Royal area as well as Osman (1977) [19] in his study of epifaunal organisms on marine hard substrata. Both studies concluded that the establishment of a climax community or equilibrium of species could occur 6-12 months after initial colonization, after which time species richness and diversity should stabilize with very little fluctuation until some stochastic event affects the community.

Species diversity was expected to increase initially and then stabilize or decline as the community approached climax $[4,19,20]$. The decline in species richness at the end of the study period at 3 of the 5 sampling stations reflect the occurrence of a perturbation, such as sloughing which was observed on few sampling occasions, resulting in fewer species within the community. Since the communities were still changing with regard to species richness, it can be assumed that no definite point of cli- max had been reached.

The lack of a clearly defined climax community might also have resulted from the frequent disturbance of substrates by oyster fishermen. Substrates were often stripped of oysters, and in the process other species as well, with the latter being discarded [4]. This removal of species would result in the creation of new space for colonization [4-5].

In terms of organic structure (biomass), the expected trend was increases in total biomass and non-living organic matter followed by a subsequent increase in species diversity [20]. The latter, results from the increase in biomass which facilitates the creation of new niches/ habitats via zonation and stratification [20].

As succession progressed, especially in the early stages, gross production exceeds community respiration $(\mathrm{P}>\mathrm{R})$ facilitating the accumulation of organic materials to form soils and an increasingly larger biomass of plants and animals [21]. Additionally, net community production decreases with a corresponding increase in community respiration $[20,21]$.

Increased species diversity, a larger biomass structure and balanced energy flows are characteristic features of a mature (stable) community [20]. While total biomass compared across the five stations gave no clear trends, the biomass of shelled vs. non-shelled species suggests greater proportions of shelled species (barnacles and bivalve molluscs) only at the more stressed sites.

The study facilitated the identification of the encrusting bryozoan Schizoporella sp. as a potential indicator species, due to its high frequency of occurrence, wide distribution and relatively easy assessment of abundance (i.e. area covered). Further research is now required on the response of this bryozoans to different levels of eutrophication.

\section{Acknowledgements}

We acknowledge the assistance with field work provided by Marlon Hibbert and the staff of the Port Royal Marine Laboratory, University of the West Indies. Funding was provided in part by an Environmental Foundation of Jamaica (E.F.J) grant to Dr. Mona Webber.

\section{REFERENCES}

[1] K. Kathiresan and B. L. Bingham, "Biology of Mangroves and Mangrove Ecosystems," Advances in Marine Biology, Vol. 40, No. 2, 2001, pp. 81-251.

doi:10.1016/S0065-2881(01)40003-4

[2] B. L. Bingham, "Life Histories in an Epifaunal Community: Coupling of Adult and Larval Processes,” Ecology, Vol. 73, No. 6, 1992, pp. 2244-2259. doi: $10.2307 / 1941472$

[3] A. M. Ellison and E. J. Farnsworth, “The Ecology of Be- 
lizean Mangrove Root Fouling Communities: Patterns of Epibiont Distribution and Effects on Root Growth," Hydrobiologia, Vol. 247, No. 3, 1992, pp. 87-98. doi:10.1007/BF00008207

[4] I. M. Goodbody, "The Biology of Ascidia nigra (Savigny). II. The Development and Survival of Young Ascidians,” Biological Bulletin, Vol. 124, No. 1, 1993, pp. 3144. doi:10.2307/1539566

[5] E. J. Farnsworth and A. M. Ellison, "Scale Dependent spatial and Temporal Variability in Biogeography of Mangrove Root Epibiont Communities,” Ecological Monographs, Vol. 66, No. 1, 1996, pp. 45-66. doi: $10.2307 / 2963480$

[6] I. M. Goodbody, "Kingston Harbour, Jamaica-An Overview,” Bulletin of Marine Sciences, Vol. 73, No. 2, 2003, pp. 249-255.

[7] I. M. Goodbody, "The Ascidian Fauna of Port Royal, Jamaica I. Harbor and Mangrove Dwelling Species,” Bulletin of Marine Sciences, Vol. 73, No. 2, 2003, pp. 457476.

[8] M. M. Creary, "Spatial Distribution of Epibenthic Bryozoans Found on the Roots of Rhizopohora mangle, Kingston Harbour, Jamaica, W. I.," Bulletin of Marine Sciences, Vol. 73, No. 2, 2003, pp. 477-490.

[9] C. P. J. Jackson and M. Webber, "Sponges of the Port Royal Mangroves and Factors that Affect Their Distribution,” Jamaica Journal, Vol. 29, No. 1-2, 2005, pp. 4249.

[10] M. Begon, J. L. Harper and C. R. Townsend, "Ecology: Individuals, Populations and Communities,” 3rd Edition, Blackwell Science Ltd, 1996.

[11] D. F. Webber and P. Wilson- Kelly, "Characterization of Sources of Organic Pollution to Kingston Harbour, the Extent of Their Influence and Some Rehabilitation Recommendations," Bulletin of Marine Sciences, Vol. 73, No. 2, 2003, pp. 257-271.
[12] G. P. Alleng, "Historical Developments, Present Status and Management Guidelines for the Port Royal Mangal, Jamaica," MPhil Dissertation, University of the West Indies, Mona, 1990.

[13] G. P. Alleng, "The Fauna of the Port Royal Mangal, Kingston, Jamaica," Studies on the Natural History of the Caribbean Region, Vol. 73, No. 1, 1997, pp. 23-42.

[14] M. K. Webber and I. Goodbody, "Mangroves,” DEMO Palisadoes Project Report, National Resource Conservation Authority, Kingston Jamaica, 1998.

[15] K. O. McDonald, D. F. Webber and M. K. Webber, "Mangrove Forest Structure under Varying Environmental Conditions,” Bulletin of Marine Sciences, Vol. 73, No. 2, 2003, pp. 491-505.

[16] B. L. Bingham and C. M. Young, "Stochastic Events and Dynamics of a Mangrove Root Epifaunal Community," Marine Ecology, Vol. 16, No. 2, 1995, pp. 145-163. doi:10.1111/j.1439-0485.1995.tb00401.X

[17] K. E. Kohler and S. M. Gill, "Coral Point Count with Excel extensions (CPCe): A Visual Basic Program for the Determination of Coral and Substrate Coverage Using Random Point Count Methodology,” Computers and Geosciences, Vol. 32, No. 9, 2006, pp. 1259-1269. doi:10.1016/j.cageo.2005.11.009

[18] J. Cohen, "Statistical Power Analysis for the Behavioral Sciences,” Lawrence Erlbaum Associates Inc., Hillsdale, 1998.

[19] R. W. Osman, “The Establishment and Development of a Marine Epifaunal Community,” Ecological Monographs, Vol. 47, No. 1, 1997, pp. 37-63. doi:10.2307/1942223

[20] E. P. Odum, “Ecology,” Modern Biology Series-Holt, Rinehart and Winston Inc., New York, 1963.

[21] E. R. Pianka, "Evolutionary Ecology,” Harper and Row Publishers, New York, 1974. 